\title{
AN AUDIT ON ADMISSION OF PATIENTS WITH HEAD INJURY TO TEACHING HOSPITAL KARAPITIYA, GALLE
}

\author{
Dr. Asoka Gunaratne ${ }^{1} *$ Dr. Saman Wadanambi ${ }^{2}$ \\ ${ }^{1}$ Consultant Anaesthetist, ${ }^{2}$ Consultant Neurosurgeon, Teaching Hospital Karapitiya (THK) \\ *Corresponding author: asoka.gunaratne@yahoo.com
}

Key Words: Head injury, Glasgow coma scale.

\begin{abstract}
Background:
Head injury is a leading cause of morbidity and mortality among the young. The aim of this audit was to analyze the head injured patients admitted to the neurosurgical unit of the Teaching Hospital Karapitiya. The analysis was according to the type of injury, age, sex distribution and the functional outcome.
\end{abstract}

\section{Method:}

All details of patients admitted to the neurosurgical unit are computerized. Data collection was done retrospectively for a period of 3 months.

\section{Results:}

Patients with head injury admitted to the neurosurgical unit accounted for $37 \%$ of all admissions with trauma. The most affected age group was 20-40 years. Out of the 108 patients admitted, 91 were males giving a male: female ratio of 5.3:1. 15 patients died. Road traffic accidents (RTA) were the commonest cause of head injury.

\section{Conclusion:}

Head injury is mainly due to road traffic accidents and affects the young adult male population.

Head injury is one of the major causes of morbidity and mortality world wide. Some of those who do not succumb are permanently disabled resulting in a large cost to society.

THK is the tertiary care unit where neurosurgical facilities are available for the entire southern province. The hospital has one neurosurgical unit with one consultant neurosurgeon to cater for the direct admissions and the transfers from the rest of the province.

There are no direct admissions of trauma patients to the neurosurgical unit. They are first admitted to the on call surgical unit. At the request of the surgical team patients are seen by a medical officer of the neurosurgical unit or if necessary by the consultant. Those patients with neurological symptoms, a drop in GCS > 2 from the initial GCS or an abnormal CT finding are admitted to the neurosurgical unit. The patients who are critically ill are directly admitted to the general intensive care unit after being resuscitated in the emergency treatment unit (ETU). The neurosurgical unit has its own high dependency unit (HDU) with facilities to ventilate.

The patients are discharged from the unit when they have recovered completely or are transferred to the local hospital if they have permernent neuro surgical deficits and needs rehabilitation. Patients who have other injuries are referred to the respective specialties and are taken over by them.

\section{Patients and Methods}


We studied 108 patients in this audit. They were admitted to the neurosurgical unit from $1^{\text {st }}$ January to $30^{\text {th }}$ March 2009 with head injury. The data collection was retrospective from the unit computer which stores all details of patients including details of follow up.

The following data were obtained

1. Age of the patient.

2. Sex of the patient.

3. Type of trauma (RTA, assault, fall, fire arms, found unconscious).

4. CT findings (cerebral haemorrhage, extra dural haemorrhage, sub dural haemorrhage).

5. GCS on admission.

6. Functional outcome (complete recovery, recovery with residual effects, death).

Table 1 - Head injury as a percentage of total number of trauma between months of January to March 2009

\begin{tabular}{|l|l|l|l|}
\hline Month & Jan & Feb & Mar \\
\hline
\end{tabular}

\begin{tabular}{|l|c|c|c|}
\hline \multicolumn{1}{|c|}{ Month } & Jan & Feb & Mar \\
\hline $\begin{array}{l}\text { Number of male } \\
\text { patients }\end{array}$ & 21 & 29 & 41 \\
\hline $\begin{array}{l}\text { Number of female } \\
\text { patients }\end{array}$ & 9 & 5 & 3 \\
\hline Male : Female ratio & $2.3: 1$ & $5.8: 1$ & $13.7: 1$ \\
\hline $\begin{array}{l}\text { Total number of } \\
\text { admissions following } \\
\text { trauma }\end{array}$ & 970 & 932 & 1031 \\
\hline $\begin{array}{l}\text { Number of patients with } \\
\text { head injury }\end{array}$ & $\begin{array}{c}30 \\
(3 \%)\end{array}$ & $\begin{array}{c}34 \\
(3.6 \%)\end{array}$ & $\begin{array}{c}44 \\
(4.2 \%)\end{array}$ \\
\hline
\end{tabular}

\begin{tabular}{|l|c|c|c|}
\hline \multicolumn{1}{|c|}{ Month } & Jan & Feb & March \\
\hline $0-9$ & 1 & 1 & 2 \\
\hline $10-19$ & 2 & 2 & 6 \\
\hline $20-29$ & 9 & 5 & 5 \\
\hline $30-39$ & 3 & 5 & 10 \\
\hline $40-49$ & 4 & 7 & 9 \\
\hline $50-59$ & 3 & 5 & 2 \\
\hline$>60$ & 8 & 9 & 10 \\
\hline
\end{tabular}

Table 2 - Sex distribution of patients.

Table 3 - Age distribution of patients.

Fig 1 - Age distribution of patients from Jan to March.

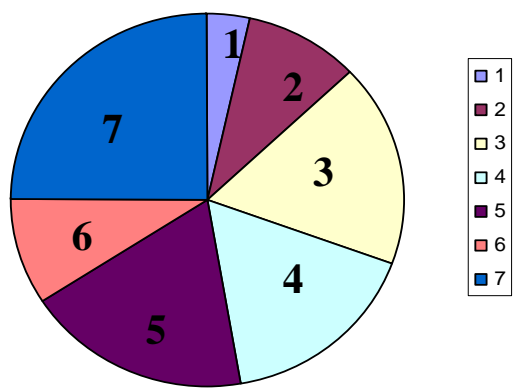

Table 4 - Type of accident.

\begin{tabular}{|l|c|c|c|}
\hline \multicolumn{1}{|c|}{ Month } & Jan & Feb & Mar \\
\hline Road traffic accident & 17 & 10 & 19 \\
\hline Assault & 3 & 13 & 9 \\
\hline Fall & 8 & 8 & 15 \\
\hline Found unconscious & 1 & 3 & 0 \\
\hline Fire arms & 1 & 0 & 1 \\
\hline
\end{tabular}




\begin{tabular}{|c|l|c|c|}
\hline $\mathbf{1}$ & RTA & 46 & $42.6 \%$ \\
\hline $\mathbf{2}$ & Assault & 25 & $23.1 \%$ \\
\hline $\mathbf{3}$ & Fall & 31 & $28.7 \%$ \\
\hline $\mathbf{4}$ & Found unconscious & 4 & $3.7 \%$ \\
\hline $\mathbf{5}$ & Fire arms & 2 & $1.8 \%$ \\
\hline
\end{tabular}

Fig 2 - Cause of injury (Jan-March).

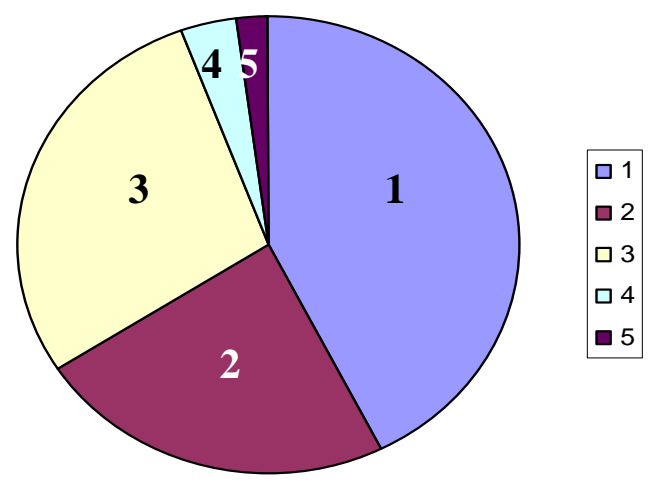

Table 5 - Average Glasgow Coma Scale on admission.

\begin{tabular}{|l|c|c|c|}
\hline \multicolumn{1}{|c|}{ Month } & Jan & Feb & March \\
\hline $14-15$ & 16 & 13 & 20 \\
\hline $8-13$ & 9 & 13 & 17 \\
\hline $4-7$ & 3 & 6 & 7 \\
\hline 3 & 2 & 2 & 0 \\
\hline
\end{tabular}

Fig 3 - Average Glasgow coma scale (JanuaryMarch).

\begin{tabular}{|l|c|c|c|}
\hline $\mathbf{1}$ & $14-15$ & 49 & $45.4 \%$ \\
\hline $\mathbf{2}$ & $8-13$ & 39 & $36.1 \%$ \\
\hline $\mathbf{3}$ & $4-7$ & 16 & $14.8 \%$ \\
\hline $\mathbf{4}$ & 3 & 4 & $3.7 \%$ \\
\hline
\end{tabular}

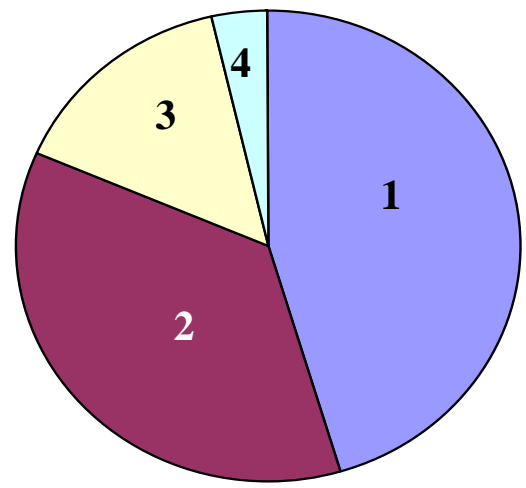

Table 6

\begin{tabular}{|l|c|c|c|}
\hline \multicolumn{1}{|c|}{ Month } & Jan & Feb & Mar \\
\hline Extra dural haemorrhage (EDH) & 5 & 2 & 1 \\
\hline Sub dural haemorrhage (SDH) & 4 & 7 & 9 \\
\hline Intra cerebral haemorrhage (ICH) & 9 & 9 & 3 \\
\hline Cerebral contusion & 6 & 5 & 9 \\
\hline Depress fracture of skull & 3 & 9 & 5 \\
\hline $\begin{array}{l}\text { Others (sub arachnoid haemorrhage / } \\
\text { cerebral oedema) }\end{array}$ & 4 & 11 & 7 \\
\hline
\end{tabular}

Fig 4 - CT Finding.

\begin{tabular}{|c|l|c|c|}
\hline $\mathbf{1}$ & EDH & 8 & $7.4 \%$ \\
\hline $\mathbf{2}$ & SDH & 20 & $18.5 \%$ \\
\hline $\mathbf{3}$ & ICH & 21 & $19.4 \%$ \\
\hline $\mathbf{4}$ & Contusion & 20 & $18.5 \%$ \\
\hline $\mathbf{5}$ & Fracture & 17 & $15.7 \%$ \\
\hline $\mathbf{6}$ & Others & 22 & $20.4 \%$ \\
\hline
\end{tabular}

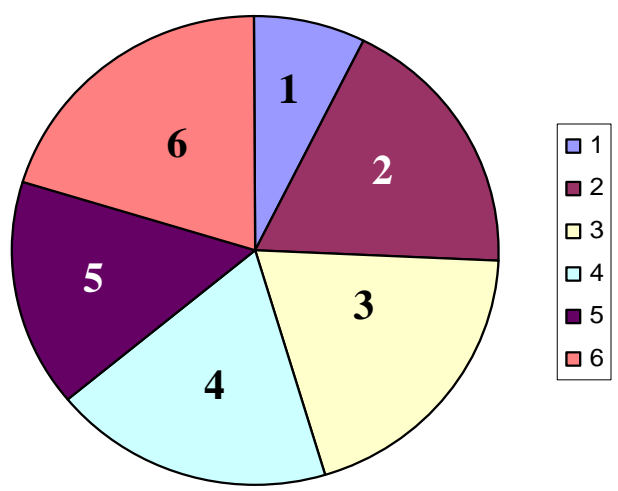

Table 7 - Functional outcome of patients.

\begin{tabular}{|l|c|c|c|}
\hline \multicolumn{1}{|c|}{ Month } & Jan & Feb & Mar \\
\hline Full recovery & 21 & 20 & 29 \\
\hline $\begin{array}{l}\text { Recovery with } \\
\text { residual effects }\end{array}$ & 6 & 6 & 9 \\
\hline Vegetative state & 1 & 0 & 1 \\
\hline Death & 2 & 8 & 5 \\
\hline
\end{tabular}


Fig 5 - Functional Outcome.

\begin{tabular}{|c|l|c|c|}
\hline $\mathbf{1}$ & Full recovery & 70 & $64.8 \%$ \\
\hline $\mathbf{2}$ & Residual effects & 21 & $19.4 \%$ \\
\hline $\mathbf{3}$ & Vegetative state & 2 & $1.85 \%$ \\
\hline $\mathbf{4}$ & Death & 15 & $13.9 \%$ \\
\hline
\end{tabular}

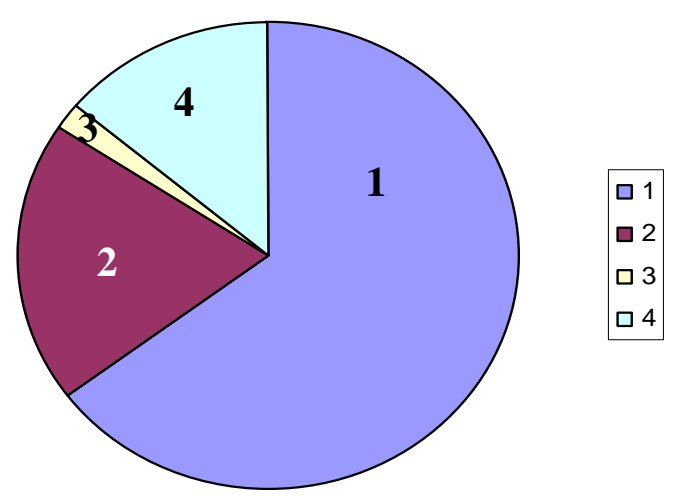

\section{Discussion}

Traumatic brain injury is a major cause of morbidity and mortality world wide. Young males within the age group of 20 - 40 years were affected most. There was also a significant number from the elderly population (25\%). When looking at the type of trauma, RTA had the highest incidence. CT findings showed a mass lesion in $64 \%$ of the patients. Vast majority of the patients recovered completely (64\%). Only 15 deaths (13.9\%) were reported.

The primary brain damage caused at the time of injury is irreversible. Some of the patients, who live to reach the hospital die later mainly due to secondary brain damage. Hypoxia, hypotension and increased intracranial pressure are the main causes of secondary brain damage ${ }^{1}$. It has been shown that a single episode of hypotension increases the mortality and morbidity significantly ${ }^{2}$. When patients get admitted to the local hospital where neurosurgical facilities are not available, a delay occurs in the admitting and transfer process. This time period is detrimental in the head injured patient where secondary brain injury is a concern ${ }^{3}$. Poor resuscitation and improper management at the local hospital and during transport are equally important causes of secondary brain damage ${ }^{4}$.

\section{Conclusion and Recommendations}

It can be concluded from the audit that young adult males are the most vulnerable to head injury. RTA is the leading causative factor.

1. Road discipline should be stressed and taught from school level.

2. There should be better transfer and communication facilities between health institutions.

3. In hospitals where a CT is available without a neurosurgical facility, a computer link should be established with the closest available facility.

4. Medical staff in peripheral hospitals should have adequate knowledge and training in resuscitation of the trauma patient.

\section{References}

1. Muhmmad QH. Critical care management of head injury - current concepts. Sri Lankan Journal of Anaesthesiology 2008; 16(2): 81-83

2. Chestnuts RM, Marshall LF, Klauber MR. The role of secondary brain injury in determining outcome from severe head injury. Journal of Trauma 1993; 34: 216-222.

3. Veerasingam EQ. An analysis of outcome of head injury patients admitted to the accident service neurosurgical intensive care unit at the National Hospital of Sri Lanka. Sri Lankan Journal of Anaesthesiology 2005; 13: 30-35.

4. Baethmann A, Eriskat J, Stofel M et al. Special aspects of severe head injury: recent developments. Current Opinion in Anaesthesiology 1998; 11; $193-$ 200. 